\title{
Profile of Bacteria and Short Chain Fatty Acids of Caecal Digesta in Malnourished Rat Fed Goat Milk Yoghurt
}

\author{
Nurliyani $^{1, *}$, BJ. Istiti Kandarina ${ }^{2}$, Sari Kusuma ${ }^{3}$, Yunita Dewi Trisnasari ${ }^{3}$, Feny Prabawati ${ }^{1}$ \\ ${ }^{1}$ Department of Animal Product Technology, Faculty of Animal Science, Universitas Gadjah Mada, Yogyakarta, Indonesia \\ ${ }^{2}$ Department of Public Health, Faculty of Medicine, Universitas Gadjah Mada, Yogyakarta, Indonesia \\ ${ }^{3}$ Department of Nutrition and Health, Faculty of Medicine, Universitas Gadjah Mada, Yogyakarta, Indonesia \\ *Corresponding author: nurliyani@yahoo.com
}

Received October 05, 2014; Revised November 03, 2014; Accepted December 03, 2014

\begin{abstract}
The intestinal microbiota is an important determinant for general health of the human body, and disturbance of the proper balance of microbiota is involved in several pathologies. The profile of gastrointestinal microbiota can be influenced by nutritional factors and or health status of individuals. This study aimed to determine the effect of goat milk yogurt on the profile of caecal bacteria and short chain fatty acid (SCFA) in malnourished rats. Yoghurt was prepared by using of pasteurized goat milk with adding the Lacto-B powder containing Lactobacillus acidophilus, Sterptococcus thermophilus and Bifidobacterium longum. Male malnourished Wistar rats 3 weeks old were created using standard feed restriction up to $50 \%$ of normal rats for $21 \mathrm{~d}$. After $21 \mathrm{~d}$, the rats continued to restricted feeding and supplemented with goat milk yoghurt for $7 \mathrm{~d}$. The rats were killed and analyzed the profile of caecal bacteria and SCFA. There were no significantly differences in the lactic acid bacteria (LAB) and bifidobacteria in both of caecal digesta of malnourished or normal rats fed yoghurt and control rats. However, the amount of $E$. coli was higher in malnourished rats than the normal rats. The acetic acid of caecal digesta was lower in the rats fed goat milk yoghurt than the control rats, whereas the butyric acid was higher in the caecal digesta of normal rats compared to the malnourished rats. The $\mathrm{pH}$ and moisture of caecal digesta in rats fed yoghurt were not significantly different from the control. In conclusion, goat milk yoghurt supplemented up to $2.0 \mathrm{ml} / 100 \mathrm{~g}$ body weight for $7 \mathrm{~d}$ had no effect on profile of caecal bacteria and physical properties and could not increase of caecal SCFA in malnourished and normal rats. Malnourished condition could increase the number of $E$. coli, decrease the butyric acid and weight of caecal.
\end{abstract}

Keywords: Goat milk yoghurt, Caecal bacteria, SCFA, Malnourished rat

Cite This Article: Nurliyani, BJ. Istiti Kandarina, Sari Kusuma, Yunita Dewi Trisnasari, and Feny Prabawati, "Profile of Bacteria and Short Chain Fatty Acids of Caecal Digesta in Malnourished Rat Fed Goat Milk Yoghurt.” Journal of Food and Nutrition Research, vol. 2, no. 12 (2014): 1015-1020. doi: 10.12691/jfnr-2-12-24.

\section{Introduction}

The gastrointestinal tract is a complex and dynamic network where an intricate and mutualistic symbiosis modulates the relationship between the host and the microbiota in order to establish and ensure gut homeostasis [1]. The cecum itself is part of gastrointestinal tract, a pouch that connects the large and small intestines. Food is temporarily stored in the cecum while helpful bacteria digest the cellulose found in plant cells. Most herbivores such as the rat have a large cecum [2].

Normally, the gastrointestinal tract of mammals is colonized with an extraordinarily large number of highly diverse microorganisms termed the commensal microbiota, predominantly the colon, harbors the greatest number and diversity of organisms, primarily bacteria [3,4]. Intestinal microbiota interact with the host digestive and immune systems [5], provides positive or negative effects on the health of the host [6].

The positive effects of gut microbiota including playing a pivotal role in nutrient digestion and energy recovery, as a source of vitamins [7], SCFA (especially butyrate) production [5], protect the intestine against colonization by exogenous pathogens [8], and regulating the balance and homeostasis of different helper $\mathrm{T}$ cell populations in the lamina propria and further emphasize the critical role that the microbiota play in the development of the immune system [4]. Protective effects of commensal bifidobacteria were attributed primarily to the production of acetate that improves intestinal defence mediated by epithelial cells and thereby protects the host against lethal infection [9]. Furthermore, butyrate is the primary energy source for colonocytes, is mainly produced by Clostridium cluster IV and XIVa [10]. Negative effects of the gut microbiota including production of putrefactive compound, such as volatile basic $-\mathrm{N}$, ammonia-N, indole, p-cresole, and sulfide [11]. 
Protein malnutrition disrupts the normal ecology of the microflora affecting strictly anaerobes, impairs host immune response and antibacterial defenses, enhances the susceptibility to infection, and leads to mucosal atrophy, impaired child development, increased mortality rate and individuals who come to function in suboptimal ways $[12,13]$. According to [14], the mild malnutrition or first degree when the weight deficit reached 10-25\%; moderate or second degree when the weight deficit reached $25-40 \%$; and severe or third degree when the weight deficit was greater than $40 \%$ of that of age-matched control rats.

Studies in animal models indicate that goat milk might have beneficial effects on malabsorption disorders and inflammatory bowel diseases [15]. In the previous study, administration of fermented milk maintained the concentrations of the total SCFAs at the same levels as before administration 5- fluoracil into mice, and suggest that the protective effect of oral administration of fermented milk against the endogenous $E$. coli infection resulted from prevention of any abnormal increase in $E$. coli levels via normalization of the 5-fluoracil-induced disruption of the intestinal environment [16].

Lacto-B is a non dairy powder-containing multi-species probiotic consists of Bifidobacterium longum, Lactobacillus acidophilus, and Streptococcus thermophilus, which in Indonesia known as treatment for diarrhea. So far the Lacto-B powder was never used in the production of yoghurt. Multi-strain and multi-species probiotics have improved functionality as compared to single strain [17]. The growth of probiotic will increase if there is source of prebiotic. Acording to [18], goat milk showed rich in sources of prebiotic oligosaccharides that resemble breast milk oligosaccharides [19], and in contrast to other prebiotics such as inulin or frukto short-chain oligosaccharides [20]. The aim of the present study, therefore, was to determine the effect of goat milk yoghurt prepared by Lacto-B powder on the profil of caecal bacteria and SCFA in malnourished rats.

\section{Materials and Methods}

\subsection{Yoghurt Preparation}

Yoghurt was prepared from goat milk of Etawah Crossedbred from Indonesia and culture of Lacto-B powder. Goat milk was pasteurized at $85^{\circ} \mathrm{C}$ for $30 \mathrm{~min}$ and cooled to $43-45^{\circ} \mathrm{C}$. After cooled, pasteurized goat milk was inoculated directly with $3 \%$ Lacto-B powder (Novell Pharmaceutical Laboratories) containing Streptococcus thermophilus, Lactobacillus acidophilus and Bifidobacterium longum and incubated at $45^{\circ} \mathrm{C}$ for $6 \mathrm{~h}$ [21].

\subsection{Animals Experimental}

Three week old male Wistar rats weighing 25.5-41.0 g, were individually caged and housed. During $7 \mathrm{~d}$ the rats fed unrestricted amounts of a standard laboratory diet AIN-93G [22] and then randomly assigned into two groups: one maintained in the same conditions (control) and another group fed $50 \%$ of the intake of the control's (restricted or malnourished) [23] for $21 \mathrm{~d}$. Both groups were allowed to drink water ad libitum. After $21 \mathrm{~d}$, the rat were assigned to four groups: 1) Normal rats (NC), 2)
Normal rats with goat milk yoghurt (NY), 3) Malnourished rats (MC), and 4) Malnourished rats with goat milk yoghurt (MY). MC and NC groups (control without yoghurt) were given aquadest with a volume equal to the volume of treated yoghurt. Aquadest as control or yoghurt were given orally with force feeding. The dose of goat milk yoghurt was $2.0 \mathrm{ml} / 100 \mathrm{~g}$ body weight/day, whose consumption is equivalent to the children consumption of $100 \mathrm{ml}$ yoghurt/day [24]. Each group of rat using 7 replications ( $n=7$ rats). All of groups were treated for $7 \mathrm{~d}$, and then were killed and sampled. Caecum of the rats was taken for analysis of profile bacteria, SCFA concentration, $\mathrm{pH}$ and moisture content. Design of the experimental groups in this study showed on Figure 1. All procedures related to animal experiment were conducted following the recommendation of Medical and Health Research Ethics Committee (MHREC) Faculty of Medicine Universitas Gadjah Mada, Indonesia (KE/FK/753/EC).

\subsection{Analysis of Caecal Bacteria}
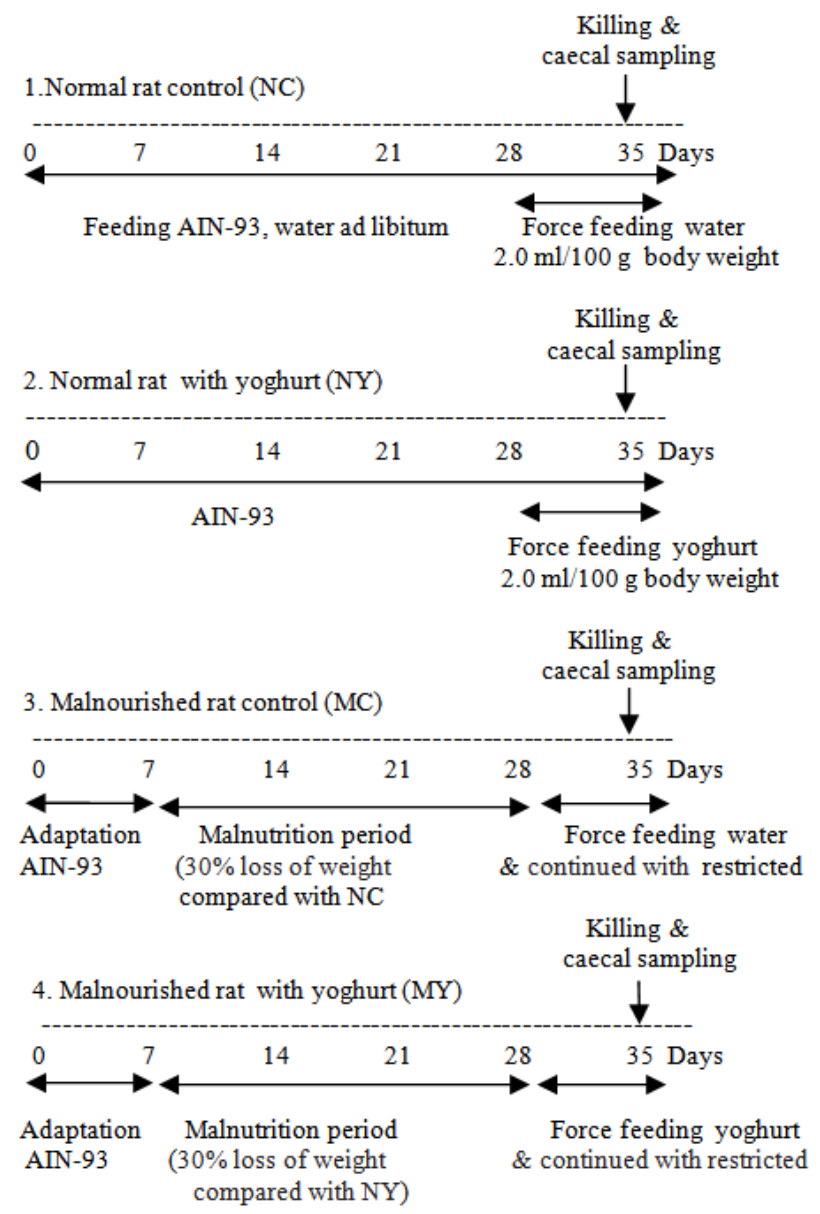

Figure 1. Design of the experimental groups under study (1.NC, 2.NY, 3. MC, 4. MY)

The caecal contents were aseptically collected. The samples for bacterial analysis were diluted in a 10 -fold series with $9 \mathrm{ml}$ physiological $\mathrm{NaCl}$. About $0.1 \mathrm{ml}$ of $10^{-5}$ and $10^{-6}$ dilutions (appropriate decimal dilutions) were spread on the surface of each agar plate. This was subjected to incubation at $37^{\circ} \mathrm{C}$ for $48 \mathrm{~h}$ for $\mathrm{LAB}$ and Bifidobacteria, and $24 \mathrm{~h}$ for $E$. coli. To determine the total LAB, Bifidobacteria and E. coli populations, the colonies formed were counted and expressed as log CFU/g wet 
weight of caecal digesta [25]. Lactic acid bacteria was determined on modified deMan, Rogosa and Sharpe (MRS) agar (Merck) containing 100 ppm $\mathrm{NaN}_{3}$ [26] and $100 \mathrm{ppm} \mathrm{CaCO}_{3}$ [27]. Lactic acid is strong enough to dissolve calcium carbonate and that can be seen as a clear area in the agar. Thus, in the isolation process clear areas indicate lactic acid bacteria [28]. Bifidobacteria population was determined on MRS agar supplemented with $0.05 \%$ of L-cysteine- $\mathrm{HCl}$ and $0.2 \%$ of bile salts [29]. Tryptone Bile X- glucoronic medium (TBX) used to determine E. coli (Oxoid, Code: CM0945).

\section{4. pH, SCFA and Moisture Analysis}

Measurement of $\mathrm{pH}$ and SCFA concentrations were determined according to the procedure of [25]. For $\mathrm{pH}$ determination, the caecal contents was diluted 1:3 in aquabidest and immediately after sampling, measured with a pH- meter (HANNA-HI 98103). For analysis of SCFA concentrations, frozen caecal samples was thawed, and centrifuged at 3,500 r.p.m. for $20 \mathrm{~min}$ and the supernatans was analysed with a Shimadzu Model GC-8A, Kyoto, Japan [25]. Condition of GC: Capillary column with 10 \& SP-1200: $1 \mathrm{~mol} / \mathrm{L} \mathrm{H}_{3} \mathrm{PO}_{4}$ in 80/100 mesh Chromosorb WAW (Supelco), and nitrogen as a gas carrier at flow rate $75 \mathrm{ml} / \mathrm{min}$. Temperature of oven, detector and injector was $125^{\circ} \mathrm{C}, 175^{\circ} \mathrm{C}$ and $180^{\circ} \mathrm{C}$, respectively. Caecal moisture contents was analyzed according to [30].

\subsection{Statistical Analysis}

All data were analyzed by Two Way ANOVA (Normal and Malnourished rat x Control and Goat milk yoghurt).

\section{Results and Discussion}

Shown on Table 1, goat milk yoghurt prepared from Lacto-B powder had no effect on the profile of bacteria of caecal digesta in malnourished and normal rats. This may be due the dose of goat milk yoghurt was too low and duration of this feeding period was also too short. Although oligosaccharides present in goat milk yoghurt but not enough doses to support probiotics. Different from the other study which using enough doses and feeding period of probiotic and prebiotics by [31], the daily supplementation with $10^{9}$ (cfu) $L$ acidophilus and fructooligosaccharides (3 g) for 4 - 8 ws to healthy humans increased fecal LAB by wk $6-8$. According to [32], intake of low $(1.5 \mathrm{~g} / \mathrm{kg})$ and high $(7.5 \mathrm{~g} / \mathrm{kg})$ dosage of probiotics and prebiotics (inulin from chicory) mixture (synbiotic powder) for 8 wk significantly improved the ecosystem of the intestinal tract by increasing the probiotics population and digestive enzyme activities in rats. In addition, the mean fecal lactobacilli and bifidobacterium counts also increased and enterobacteriaceae decreased after 3 wk daily consumption of regular yoghurt, synbiotic yoghurt and traditional fermented sobya [33]. Differences in the survival of lactic acid bacteria in in vivo conditions, depending on the combination of bacteria in the fermented milk. The ingestion of lactic acid bacteria influences the composition and/or metabolism of endogenous microbiota. The new association of $L$. casei with yogurt cultures has specific effects of its own that differ from the simple addition of the effects of $L$. casei-fermented milk and yogurt. These effect may offer potential benefits for health [34].

Table 1. Profile of bacteria ( $\log \mathrm{CFU} / \mathrm{g}$ ) of caecal digesta in malnourished and normal rats treated with goat milk yoghurt

\begin{tabular}{|c|c|c|c|}
\hline & Goat milk yoghurt & Control & Average \\
\hline LAB & & & \\
\hline Malnourished & $8.09 \pm 0.53$ & $8.18 \pm 0.27$ & $8.13 \pm 0.40$ \\
\hline Normal & $8.04 \pm 0.69$ & $7.75 \pm 0.73$ & $7.89 \pm 0.69$ \\
\hline Average & $8.06 \pm 0.58$ & $7.96 \pm 0.57$ & $8.01 \pm 0.57^{\text {ns }}$ \\
\hline Bifidobacteria & & & \\
\hline Malnourished & $7.65 \pm 0.55$ & $8.00 \pm 0.64$ & $7.82 \pm 0.60$ \\
\hline Normal & $7.76 \pm 0.73$ & $7.12 \pm 0.57$ & $7.44 \pm 0.71$ \\
\hline Average & $7.70 \pm 0.62$ & $7.56 \pm 0.74$ & $7.63 \pm 0.67^{\text {ns }}$ \\
\hline Escherichia coli & & & \\
\hline Malnourished & $4.27 \pm 0.88$ & $4.88 \pm 0.30$ & $4.55 \pm 0.72^{\mathrm{a}}$ \\
\hline Normal & $3.72 \pm 0.83$ & $3.51 \pm 1.30$ & $3.61 \pm 1.06^{\mathrm{b}}$ \\
\hline Average & $4.02 \pm 0.86^{\text {a }}$ & $4.13 \pm 1.18^{\mathrm{a}}$ & $4.08 \pm 1.01$ \\
\hline
\end{tabular}

ns: not significant

a, b: the different letter in the same column or the same row indicates significantly different $(\mathrm{P}<0.05)$

The result of this study (Table 1) indicated that malnourihed rats have more $E$. coli than the normal rats, because according to epidemiological and experimental observations have proven that malnourished children are more susceptible to infectious disease; therefore, protein calorie malnutritiom is considered a strong risk factor for higher morbidity and mortality rates in infectious disease [13].

Goat milk yoghurt prepared from Lacto-B powder (Table 2) had no effect on propionic and butyric acid, but the acetic in rat caecal decreased significantly $(\mathrm{p}<0.05)$. Since goat milk yoghurt in this study could not increase the number of caecal LAB and bifidobacteria, so that no increase in the metabolites produced (including SCFA). The dose of goat milk yoghurt in this study not enough to increase the total number of LAB and bifidobacteria in the caecal that produce SCFA. Streptococcus thermophilus, Lactobacillus acidophilus and Bifidobacterium longum combination in Lacto-B powder which was used to make yoghurt, tending to be negative effect (i.e. decreased caecal acetic acid). Similar to the previous study, consumed Lactobacillus acidophillus (LAC) $1 \times 10^{9} \mathrm{cfu}$ for $4 \mathrm{wk}$ had negative effect in healthy humans (i.e.increased fecal protein catabolites), whereas fructooligosaccharides (FOS) tending to be beneficial (decreased fecal protein catabolites) [31]. In the other study, the fecal SCFA concentrations in male subjects were also unchanged following the dietary intervention for 3 wk with regular yoghurt, synbiotic yoghurt, sobya and placebo. This result was interpreted the negative response to short duration of intervention or to the need to use new combinations of LAB strains [33]. However, according to the study by [35], that probiotic bacteria affect both the carboxylic acid pattern and the site of carboxylic acid release in the hindgut of rats. The indigestible carbohydrate had more pronounced effects on both the profiles and the caecal concentrations and pools of carboxylic acid. Thus, based on several studies mentioned above, can be explained that the differences in the subject, a combination of probiotics, duration of interventions and dose of probiotics may influence the production of caecal SCFA. Possibility variations in human diet causes a given probiotic effect is not significant. Related to insignificant caecal SCFA in this study, thought to be caused by low doses of yoghurt 
and in short time interventions. This is understandable because this study uses the rat subject were given the same standard diets, so as to reduce the effect of variation of diets other than the treatment given.

Table 2. SCFA concentration (mMol) of wet caecal digesta in malnourished and normal rats treated with goat milk yoghurt

\begin{tabular}{|c|c|c|c|}
\hline & Goat milk yoghurt & Control & Average \\
\hline \multicolumn{4}{|l|}{ Acetic acid } \\
\hline Malnourished & $40.03 \pm 3.77$ & $57.45 \pm 15.59$ & $48.74 \pm 14.16^{\mathrm{a}}$ \\
\hline Normal & $47.30 \pm 5.69$ & $49.64 \pm 11.44$ & $48.47 \pm 8.76^{\mathrm{a}}$ \\
\hline Average & $43.66 \pm 5.98^{\mathrm{a}}$ & $53.54 \pm 13.75^{b}$ & $48.60 \pm 11.55$ \\
\hline \multicolumn{4}{|l|}{ Propionic acid } \\
\hline Malnourished & $10.29 \pm 1.55$ & $14.70 \pm 4.96$ & $12.49 \pm 4.21$ \\
\hline Normal & $12.59 \pm 3.24$ & $13.68 \pm 5.45$ & $13.13 \pm 4.35$ \\
\hline Average & $11.44 \pm 2.72$ & $14.19 \pm 5.04$ & $12.81 \pm 4.21^{\mathrm{ns}}$ \\
\hline \multicolumn{4}{|l|}{ Butyric acid } \\
\hline Malnourished & $2.77 \pm 2.18$ & $2.29 \pm 0.68$ & $2.55 \pm 1.62^{\mathrm{a}}$ \\
\hline Normal & $3.97 \pm 1.70$ & $5.27 \pm 2.24$ & $4.73 \pm 2.06^{b}$ \\
\hline Average & $3.27 \pm 2.00^{\mathrm{a}}$ & $3.89 \pm 2.25^{\mathrm{a}}$ & $3.59 \pm 12.12$ \\
\hline
\end{tabular}

Propionic and butyric acids affect metabolic parameters, low-grade systemic inflammation, insulin resistance and obesity. The formation of propionic and butyric acids in the caecum is reflected by increased concentrations in the aortic blood [36].

Malnourished rats in this study showed lower butyric acid compared to normal rats (Table 2) due the malnourished rats have more number of E.coli which cause infection and may cause inflammation. This condition would change the ratio of gut microbiota. Since the number of LAB and bifidobacteria in the caecal of malnourished rats did not increase, then the resulting SCFA was also not increase and even decreasing butyric. At the intestinal level, butyrate plays a regulatory role on the transepithelial fluid transport, ameliorates mucosal inflammation and oxidative status, reinforces the epithelial defense barrier, and modulates visceral sensitivity and intestinal motility [37]. Butyrate is a major metabolite in colonic lumen arising from bacterial fermentation of dietary fiber and has been shown to be a critical mediator of the colonic inflammatory response [38]. Butyrate is mostly used by colonocytes as an energy source [39] could be metabolized by colonic epithelium, was shown to decrease the risk of mucosal damage. In contrast to butyrate, propionic and acetic acid may have similar but less prominent effects. These acids are associated mainly with metabolic effects [40]. This butyrate possesses both preventive and therapeutic potential to counteract inflammation-mediated ulcerative colitis (UC) and colorectal cancer. One mechanism underlying butyrate function in suppression of colonic inflammation is inhibition of the IFN- $\gamma / \mathrm{STAT} 1$ signaling pathways at least partially through acting as a histone deacetylase (HDAC) inhibitor [38]. The role of butyrate differs between normal and cancerous cells. This is known as the "butyrate paradox". Butyrate inhibits colonic tumor cells, and promotes healthy colonic epithelial cells [41]. As for the level of SCFAs also differs remarkably between the faecal samples of healthy subjects and these of Inflammatory Bowel Disease (IBD) patients [42].

Similar to the previous study by [25], that total SCFA concentrations were reduced remarkably in proportion to the food restriction rate, especially butyrate which decreased strikingly compared with the other SCFAs. The results means that food restriction may influence the physiological processes through alterations in the gut microbiota and its metabolic products. In addition, the other study in fecal sample of IBD showed decreased dramatically in butyric, and also acetic and propionic acids compared to the healthy subjects [42].

The were no significantly differences of $\mathrm{pH}$ value and moisture content of caecal digesta in malnourished and normal rats fed goat milk yoghurt (Table 3). Because no increase of SCFA produced in the rat caecal by the administration of yogurt then it did not decrease the caecal $\mathrm{pH}$. This result in this study similar to the study by [43], that yoghurt supplemented with $B$. longum at $250 \mathrm{ml}$ per day for 2 wk to healthy volunteers was not change the fecal $\mathrm{pH}$ (diversity of diet may be the reason), eventhough the SCFA production was increase. When ingestion of this yoghurt was stopped, then levels of SCFA declined slowly. As a result of increasing concentrations of acidic fermentation products, the luminal $\mathrm{pH}$ in the proximal colon is lower. This $\mathrm{pH}$ seems to boost the formation of butyrate, as mildly acidic $\mathrm{pH}$ values allow butyrateproducing bacteria to compete against Gram-negative carbohydrate-utilizing bacteria, such as Bacteroides spp. [37]. In addition, yoghurt is a low $\mathrm{pH}$ food and SCFA accumulation in caecal leads to acidic $\mathrm{pH}$ [44].

Table 3. Value of $\mathrm{pH}$ and moisture content of caecal digesta in malnourished and normal rats treated with goat milk yoghurt

\begin{tabular}{|c|c|c|c|}
\hline & Goat milk yoghurt & Control & Average \\
\hline pH & & & \\
\hline Malnourished & $7.22 \pm 0.38$ & $7.12 \pm 0.32$ & $7.17 \pm 0.34$ \\
\hline Normal & $7.28 \pm 0.29$ & $7.13 \pm 0.36$ & $7.20 \pm 0.33$ \\
\hline Average & $7.25 \pm 0.33$ & $7.12 \pm 0.33$ & $7.18 \pm 0.33^{\mathrm{ns}}$ \\
\hline Moisture (\%) & & & \\
\hline Malnourished & $83.47 \pm 2.27$ & $85.11 \pm 1.31$ & $84.29 \pm 1.97$ \\
\hline Normal & $84.37 \pm 1.24$ & $84.59 \pm 0.93$ & $84.48 \pm 1.06$ \\
\hline Average & $83.92 \pm 1.82$ & $84.85 \pm 1.12$ & $84.38 \pm 1.56^{\mathrm{ns}}$ \\
\hline
\end{tabular}

Administration of goat milk yoghurt in this study did not affect the caecal moisture content in malnourished and normal rats (Table 3), due the caecal SCFA was not increase. In the previous study, the fecal moisture content tended to increase when either yoghurt supplemented with Bifidobacterium longum or standard yoghurt was ingested in healthy volunteer. The increase in moisture is considered to reflect the increase in organic acid levels and it may facilitate excretion. Consumption of yoghurt supplemented with $B$. longum may be expected to alleviate constipation [37]. According to [45], there is weak positive correlations between faecal water content and the major SCFAs, acetic, propionic and butyric acids. However, in other study showed that probiotic fermented milk beverage that contains Lactobacillus casei at 40 billion bacterial cells/bottle for 4 wk (probiotics, 1 bottle/day), has an intestine-conditioning effect by improving the stool quality (hardened) and increasing the intrinsic bifidobacteria in healthy individuals with soft stool and also the water content of the stools was lower in the probiotic group than in the placebo group [46]. This means the kind and dose of probiotics can affect the quality and moisture contents of stool.

Shown on Table 4, caecal weight of malnourished rat was lower $(\mathrm{p}<0.05)$ than normal rats, and the caecal weight of rat treated with yoghurt was also lower than the control rat. 
Restriction feeding 50\% intake from the normal feeding in this study could decrease the caecal weight, and feeding yoghurt during $7 \mathrm{~d}$ after restriction feeding could not increase the caecal weight. This result similar to the study by [47], that feeding B.longum without inulin for 1 wk did not increase caecal weight nor did it decrease $\mathrm{pH}$ of the caecal contents. This may be the dose of yoghurt was too low and also short period of yoghurt feeding. In the previous study by [44], caecal weight of albino rats fed plain yoghurt, xylooligosaccharide enriched yoghurt and xylooligosaccharide during $21 \mathrm{~d}$ was higher than the control rats. The other study showed that administration of fermentable carbohydrates such as inulin had a marked influence on both caecal weight and caecal $\mathrm{pH}$ [48]. Thus, it can be interpreted that caecal weight depends on the dose and duration of feeding the microbial or probiotic combinations and also depends on prebiotics or it combination with probiotics.

Table 4. Caecal weight in malnourished and normal rats treated with goat milk yoghurt

\begin{tabular}{|c|c|c|c|}
\hline & Goat milk yoghurt & Control & Average \\
\hline Caecal weight (g) & & & \\
\hline Malnourished & $1.42 \pm 0.14$ & $1.67 \pm 0.33$ & $1.54 \pm 0.27^{\mathrm{a}}$ \\
\hline Normal & $1.97 \pm 0.40$ & $2.32 \pm 0.36$ & $2.14 \pm 0.40^{\mathrm{b}}$ \\
\hline Average & $1.70 \pm 0.40^{\mathrm{a}}$ & $1.99 \pm 0.47^{\mathrm{b}}$ & $1.84 \pm 0.45$ \\
\hline
\end{tabular}

a, b: the different letter in the same column or the same row indicates significantly different $(\mathrm{P}<0.05)$

Probiotic yoghurt and prebiotic diet leading towards production of SCFA in the large intestine, and these SCFA serve as energy source to increase cell density along with regularized cell proliferation $[37,44]$. This acid has a trophic effect on the intestinal epithelium, by increasing the blood flow and stimulating mucosal proliferation [40]. Thus, the caecal weight could increase, and this is not occur in malnourished rats.

\section{Conclusion}

Goat milk yoghurt by using Lacto-B powder given at a low dose ( $2 \mathrm{ml} / 100 \mathrm{~g}$ body weight) and short time period (7 d) had no effect on the profile of caecal bacteria, caecal physical properties and could not increase of SCFA in malnourished rats. Furthermore, malnourished rats have more number of Escherichia coli, so that resulting in lower of caecal butyrate and caecal weight than normal rats.

\section{Acknowledgement}

This research was supported partially by a grant from Public Funds of Universitas Gadjah Mada (Nomor LPPMUGM/2175/BID.I/2012 TANGGAL 11 JULI 2012).

\section{References}

[1] Lopetuso, L.R., Scaldaferri, F., Petito, V. and Gasbarrini, A. "Commensal Clostridia: leading players in the maintenance of gut homeostasis”. Gut Pathogens 5 (23), 1-8, 2013.

[2] Sowash, J.R. "Rat Dissection", 1-9, May 2009. https://jrsowash.wikispaces.com/file/view/rat.student.pdf [Accessed October, 2014].

[3] Sears, C.L. “A dynamic partnership: Celebratingour gut flora”. Anaerobe 11, 247-251, 2005
[4] Ivanov, I.I., Frutos, R.D.L., Manel, N., Yoshinaga, K., Rifkin, D.B., Sartor, R.B., Finlay, B.B. and Littman, D.R. "Specific microbiota direct the differentiation of Th17 cells in the mucosa of the small intestine”. Cell Host Microbe. 4 (4), 337-349, October 2008.

[5] Lin, X.B., Farhangfar, A., Valcheva, R., Sawyer, M.B., Dieleman, L., Schieber, A., Ganzle, M.G. and Baracos, V. "The role of intestinal microbiota in development of irinotecan toxicity and in toxicity reduction through dietary fibres in rats”. PLOS ONE 9 (1), e83644, 1-11, 2014.

[6] Manson, J.M., Rauch, M. and Gilmore, M.S. "Microbiota and Regulation of the Immune System” Edited by Huffnagle, G.B. and Noverr, M.C. Landes Bioscience and Springer Science+Business Media, 2008

http://www.landesbioscience.com/pdf/02HuffnagleGilmore.pdf) [Accessed October, 2014].

[7] Rossi, M., Amaretti, A. and Raimondi, S. "Folate production by probiotic bacteria”. Nutrients 3, 118-134, 2011.

[8] Vecchio A.L and Cohen, M.B. "Fecal microbiota transplantation for Clostridium difficile infection: benefits and barriers". See comment in PubMed Commons belowCurr Opin Gastroenterol., 30 (1), 47-53, January 2014.

[9] Fukuda, S., Toh, H., Hase, K., Oshima, K., Nakanishi, Y., Yoshimura, K., Tobe, T., Clarke, J.M., Topping, D.L., Suzuki, T., Taylor, T.D., Itoh, K., Kikuchi, J., Morita, H., Hattori, M. and Ohno, H. "Bifidobacteria can protect from enteropathogenic infection through production of acetate. Nature 469, 543-547, January, 2011.

[10] Louis, P., Scott, K.P., Duncan, S.H. and Flint, H.J. "Understanding the effects of diet on bacterial metabolism in the large intestine”. J Appl Microbiol, 102 (5), 1197-1208, May 2007.

[11] Kuda, T., Yano, T., Matsuda, N. and Nishizawa, M. “ Food Chemistry 91 Inhibitory effects of laminaran and low molecular alginate against the putrefactive compounds produced by intestinal microflora in vitro and in rats”. Food Chem. 91, 745-749, 2005.

[12] Dock, D.B., Agular-Nascimento, J. E., and Latorraca, M.Q. "Probiotics enhance the recovery of gut atrophy in experimental malnutrition”. Biocell 28, 143-150, 2004.

[13] Rodríguez, L., Cervantes, E. and Ortiz, R. "Malnutrition and gastrointestinal and respiratory infections in children: A public health problem” J.Environ. Res.Public Health, 8, 1174-1205, 2011.

[14] Cortés-Barberena, E., González-Márquez, H., Gómez-Olivares, J.L. and Ortiz-Muñiz, R. "Effects of moderate and severe malnutrition in rats on splenic $\mathrm{T}$ lymphocyte subsets and activation assessed by flow cytometry”. Clin Exp Immunol. 152, 585-592, 2008.

[15] Johansson, S., "Goat Milk-Nutrition and health aspects”, 1-24, 2011. http://media.dalsspira.se/2014/03/goatmilk-nutrition-healthaspects.pdf [Accessed August, 2014].

[16] Asahara, T., Shimizu, K., Nomoto, K., Watanuki, M. and Tanaka, R. "Antibacterial effect of fermented milk containing Bifidodobacterium bre $\times$, Bifidobacterium bifidum and Lactobacillus acidophilus against indigenous Escherichia coli infection in mice” Microb Ecol Health Dis., 13, 16-24, 2001.

[17] Dash, S.K., “ Selection criteria for probiotics”, in XXXVII Dairy Industry Conference, Kala Academy, Panjim, Goa, 1-4, Feb 7-9, 2009.

[18] Wu, F.Y., Tsao, P.H., Wang, D.C., Lin, S., Wu, J. and Cheng, Y.K., "Factors affecting growth factor activity in goat milk". $J$ Dairy Sci., 89, 1951-1955, 2006.

[19] Bode, L. "Recent advances on structure, metabolism, and function of human milk oligosaccharides”. J Nutr. 136, 2127-2130, 2006.

[20] Lara-Villoslada, F., Debras, E., Nieto, A., Concha, A., Ga'lvez, J., Lo'pez-Huertas, E., Boza, J., Obled, C. and Xaus, J. "Oligosaccharides isolated from goat milk reduce intestinal inflammation in a rat model of dextran sodium sulfate-induced colitis”, Clin Nutr. 25, 477-488, 2006.

[21] Dave, R.I. and Shah, N.P., "Ingredient supplementation effects on viability of probiotic bacteria in yogurt” J Dairy Sci., 81 (11), 2804-2816, 1998.

[22] Reeves, P. G., Neilsen, F.H. and Fahey, G.C., JR., “AIN-93 Purified diets for laboratory rodents: Final report of the American Institute of Nutrition Ad Hoc Writing Committee on the Formulation of the AIN-76A Rodent Diet”. J. Nutr. 123, 19391951, 1993.

[23] Rosso, P., Keyou, G., Bassi, J.A. and Slusser, W.M. "Effect of malnutrition during pregnancy on the development of the mammary glands of rats”. J. Nutr. 111, 1937-1941, 1981. 
[24] WHO, "Food and nutrition policy for schools: A tool for the development of school nutrition programmes in the European Region”. Programme for Nutrition and Food Security. WHO Regional Office for Europe. Copenhagen, 2006.

[25] Morishita, Y. "Effect of food restriction on caecal microbiota and short-chain fatty acid concentrations in rats. Microb Ecol Health Dis., 8, 35-39, 1995.

[26] Mundt, J.O., Graham, W. F. and McCarty, I. E., "Spherical lactic acid-producing bacteria of southern-grown raw and processed vegetables”, Appl Microbiol., 15: 1303-1308, 1967.

[27] Hwanhlem, N., Buradaleng, S., Wattanachant, S., Benjakul, S., Tanic, A. and Maneera, S., "Isolation and screening of lactic acid bacteria from Thai traditional fermented fish (Plasom) and production of Plasom from selected strains”. Food Cont., 22 (3-4), 401-407, March-April 2011.

[28] Endo, A., Futagawa-Endo, Y., and Dicks, L.M., "Isolation and characterization of fructophilic lactic acid bacteria from fructoserich niches”. Syst Appl Microbiol., 32: 593-600, 2009.

[29] Gomes, A.M.P., Malcata, F.X. and Klaver, F.A.M. "Growth enhancement of Bifidobacterium lactis Bo and Lactobacillus acidophilus Ki by milk hydrolyzates”, J Dairy Sci., 81 (11), 28172825, 1998.

[30] AOAC, "Official Methods of Analysis". 14th Edition. Association of Official Analytical Chemists. Washington DC., 1990.

[31] Swanson, K.S., Grieshop, C.M., Flickinger, E.A., Bauer, L.L., Wolf, B.W, Chow J, Garleb KA, Williams JA, Fahey GC Jr. Fructooligosaccharides and Lactobacillus acidophilus modify bowel function and protein catabolites excreted by healthy humans. J Nutr., 132 (10), 3042-3050, Oct., 2002.

[32] Yang, S-C., Chen, J-Y., Shang, H-F., Cheng, T-Y., Tsou, S.C. and Chen, J-R. "Effect of synbiotics on intestinal microflora and digestive enzyme activities in rats” World J Gastroenterol, 11 (47), 7413-7417, 2005.

[33] Hussein, L., Gouda, M., Fouad, M., Labib, E., Bassyouni, R. and Mohammad, M. "Dietary intervention with yoghurt, ynbiotic yogurt or traditional fermented sobya: Bio-Potency among male adolescents using five bio-markers of relevance to colonic metabolic activities”. Food. Nutr. Sci., 5 (12), 1131-1144, 2014.

[34] Djouzi, Z., Andrieux, C., Degivry, M-C., Bouley, C. and Szylit, O., "The association of yogurt starters with Lactobacillus casei DN 114.001 in fermented milk alters the composition and metabolism of intestinal microflora in germ-free rats and in human floraassociated rats", J. Nutr., 127, 2260-2266, 1997.

[35] Nilsson, U., Nyman, M., Ahrné, S., Eilbhis, Sullivan, O., and Fitzgerald, G., "Bifidobacterium lactis Bb-12 and Lactobacillus salivarius UCC500 modify carboxylic acid formation in the hindgut of rats given pectin, inulin, and lactito", J. Nutr., 136 (8), 2175-2180, 2006

[36] Jakobsdottir, G., Jädert, C., Holm, L. and Nyman, M.E, "Propionic and butyric acids, formed in the caecum of rats fed highly fermentable dietary fibre, are reflected in portal and aortic serum”, Br J Nutr., 110 (9), 1565-1572, March 2013.

[37] Canani,. R.B., Di Costanzo, M., Leone, L., Pedata, M., Meli, R. Calignano, A. "Potential beneficial effects of butyrate in intestinal and extraintestinal diseases". World J Gastroenterol. 17 (12), 1519-1528, 2011.

[38] Zimmerman, M. A., Singh, N., Martin, P. M., Thangaraju, M., Ganapathy, V., Waller, J. L., Shi, H., Robertson, K. D., Munn, D. H. and Liu, K. "Butyrate suppresses colonic inflammation through HDAC1-dependent Fas upregulation and Fas-mediated apoptosis of T cells". Am J Physiol Gastrointest Liver Physiol., 302 (12), G1405-1415, Jun 2012.

[39] Dumas, M-E. 2011. "The Microbial-Mammalian Metabolic Axis Beyond Simple Metabolism”. Cell Metab., 13, 489-490, May, 2011.

[40] Smith, J.G., Yokoyama, W.H. and German,. J.B., "Butyric acid from the diet: actions at the level of gene expression". Crit Rev Food Sci Nutr., 38: 259-297, 1998.

[41] Vanhoutvin, S.A., Troost, F.J., Hamer, H.M., Lindsey, P.J., Koek, G.H., Jonkers, D.M., Kodde, A., Venema, K. and Brummer, R.J., "Butyrate-Induced Transcriptional Changes in Human Colonic Mucosa". In Bereswill, Stefan. PLoS ONE, 4 (8): e6759, 2009.

[42] Huda-Faujan, N., Abdulamir, A.S., Fatimah, A.B., Anas, O.M., Shuhaimi, M., Yazid, A.M. and Loong, Y.Y. "The impact of the level of the intestinal short chain fatty acids in inflammatory bowel disease patients versus healthy subjects", Open Biochem J., 4, 53-58, 2010.

[43] Ogata, T., Kingaku M., Yaeshima, T., Teraguchi, S., Fukuwatari, Y., Ishibashi, N., Hayasawa, H., Fujisawa, T. and Iino, H., "Effect of Bifidobacterium longum BB536 yogurt administration on the intestinal environment of healthy adults”, Microb Ecol Health Dis. 11, 41-46, 1999

[44] Mumtaz, S., Salim-ur-Rehman, Huma, N., and Jamil, A., "Effect of xylooligosaccharide enriched yogurt on serum profile in Albino rats” Pak. J. Nutr., 8 (11), 1756-1759, 2009.

[45] Siigur, U., Norins, K.E., Allgood, G., Schlagheck, T., Midtvedts, T. "Concentrations and correlations of faecal short-chain fatty fcids and faecal water content in man". Microb Ecol Health Dis., 7: 287-294, 1994.

[46] Matsumoto, K., Takada, T., Shimizu, K., Moriyama, K., Kawakami, K., Hirano, K., Kajimoto, O., Nomoto, K., "Effects of a probiotic fermented milk beverage containing Lactobacillus casei strain Shirota on defecation frequency, intestinal microbiota, and the intestinal environment of healthy individuals with soft stools”, J Biosci Bioeng., 110 (5), 547-552, N0v, 2010.

[47] Rowland, I. R, Rumney, C.J., Coutts, J.T. and Lievense, L.C. "Effect of Bifidobacterium longum and inulin on gut bacterial metabolism and carcinogen-induced aberrant crypt foci in rats" Carcinogenesis, 19 (2), 281-285, 1998.

[48] Rowland,I.R. and Tanaka, R., “ The effects of transgalactosylated oligosaccharides on gut flora metabolism in rats associated with a human faecal microflora”. J. Appl. Bacteriol., 74, 667-674, 1993. 